\title{
GERAKAN PEDULI LINGKUNGAN DI SEKOLAH DASAR
}

\author{
Oleh \\ Faizal Chan; Agung Rimba Kurniawan; Amalia Oktavia; Levy Citra Dewi; Arum Sari; \\ Aisyah Putri Khairadi; Sulgi Piolita \\ faizal.chan@unja.ac.id; agung.rimba@unja.ac.id; amaliaoktavia6@gmail.com; \\ Levycitradewi01@gmail.com; Arrumsarri18@gmail.com; aisyahputrikh@gmail.com; \\ sulgipiolita@gmail.com
}

Fakultas Keguruan dan Ilmu Pendidikan, Universitas Jambi, Indonesia

diterima 15 Agustus 2019, direvisi 19 September 2019, diterbitkan 1 Oktober 2019

\begin{abstract}
Abstrak
Penelitian ini bertujuan untuk mengetahui, mengkaji dan mendeskripsikan penerapan gerakan peduli lingkungan di sekolah dasar dan diharapkan dapat menumbuhkan rasa peduli lingkungan sekolah. Penelitian ini menggunakan pendekatan kaulitatif deskriptif dan jenis dalam penelitian ini adalah fenomonologi. Tempat pelaksanaan penelitian ini adalah SD Negeri 55/I Sridadi, Muara Bulian dengan subjek penelitian yaitu kepala sekolah, guru dan siswa. Data yang dikumpulkan menggunakan observasi, wawancara dan dokumentasi. Hasil penelitian ini menunjukan bahwa di SD Negeri 55/I Sridadi, Muara Bulian, Kab. Batang Hari, Provinsi Jambi menunjukan bahwa dalam gerakan peduli lingkungan di sekolah tersebut dilaksanakn melaluli program-program, seperti program Sagu Sapo serta program yang mewajibkan setiap paginya harus melakukan piket membersihkan lingkungan di sekolah. Program ini tidak hanya di laksankaan oleh siswa saja tetapi guru maupun kepala sekolah juga ikut berperan di dalam hal ini. Serta adanya sanksi bagi siswa atau guru yang tidak melaksanakan tugas piketnya. Pada saat musim kemarau siswa di instruksikan untuk membawa satu anak satu botol air untuk menyiram tanaman yang ada di lingkungan sekolah.
\end{abstract}

Kata kunci: Gerakan, Peduli Lingkungan

\begin{abstract}
This study aims to determine, study and describe the application of the movement to care for the environment in elementary schools and is expected to foster a sense of caring for the school environment. This study uses a descriptive caulative approach and the type in this study is phenomonology. The place of this research is SD Negeri 55 / I Sridadi, Muara Bulian with the subject of the research being the principal, teachers and students. Data collected using observation, interviews and documentation. The results of this study indicate that in SD Negeri 55 / I Sridadi, Muara Bulian, Kab. Batang Hari, Jambi Province shows that in the environmental care movement at the school, it is carried out through programs, such as the Sagu Sapo program and programs that require every morning to do a picket cleaning the environment at school. This program is not only carried out by students but teachers and principals also play a role in this. And there are sanctions for students or teachers who do not carry out their picket assignments. During the dry season students are instructed to bring one child one bottle of water to water the plants in the school environment.
\end{abstract}

Keywords: Movement, Environmental Care 


\section{PENDAHULUAN}

Lingkungan merupakan tempat
hidup dan tempat manusia untuk
berinteraksi. Menurut Mundiatun dan
Dariyanto (2015:42-43) mengatakan
bahwa lingkungan merupakan pemukiman
tempat hidup dan segala keadaan serta
kondisi yang ada di dalamnya yang secara
langsung maupun tidak langsung dapat
mempengaruhi tingkat kehidupan.
Lingkungan yang sehat dapat mendukung tingkat kehidupan organisme termasuk manusia. Menurut Mundiatun dan Dariyanto (2015:16) (dalam Rokhmani, 2016) lingkungan yang dikatakan sehat terjadi apabila adanya keseimbangan ekologi antara manusia dan lingkungan. Kondisi pengembangan karakter peduli lingkungan di sekolah belum terlaksana dengan baik ((Dewi P.F. \& Budimansyah, 2016). Di beberapa sekolah, telah dikembangkan strategi untuk memenuhi kebutuhan dalam upaya mengembangkan kepedulian siswa terhadap lingkungan.

Pada Sekolah Dasar Negeri Tritih Wetan 05 Jeruk Legi Cilacap dilaksanakan pengembangan karakter peduli lingkungan dengan cara: (1) Pengembangan kurikulum sekolah meliputi program pengembangan diri, pengintegrasian dalam mata pelajaran dan budaya sekolah. (2) Pengembangan proses pembelajaran kelas dengan praktek dan pengamatan langsung, sekolah dengan pengarahan dan lomba, dan luar sekolah dengan pramuka, kunjungan keluar sekolah. (3) Pengembangan kesehatan sekolah meliputi pemeliharaan ruang dan bangunan, pencahayaan dan pentilasi udara ruang kelas yang memadai, pengelolaan fasilitas sanitasi, pengelolaan kantin, pencegahan lingkungan dari jentik nyamuk, laragan dan penyuluhan rokok, dan promosi hygienedan sanitasi dengan poster serta himbauan atau ajakan. Sejalan dengan penelitian yang dilakukan oleh (Trahati, 2015).
Kemudian di SD N Tukangan Yogyakarta mengimplementasikan nilai peduli lingkungan untuk mewujudkan sekolah adhiwiyata yaitu menetapkan visi sekolah, penetapan program pendukung, penyediaan srana pendukung, kebiasaan, pembiasaan berbasis partisipasi, keteladanan, hukuman, dan penghargaan (Ngalawiyah, 2014).

Adapun perbedaan dengan kedua penelitian diatas baik dari Trahati maupun Ngalawiyah dengan penelitian ini adalah pada fokus penelitian dan seting tempat penelitian. Penelitian ini dilaksanakan di SD Negeri 55/I Sridadi sejak agustus tahun 2019.

Salah satu yang menjadi perhatian di lingkungan sekitar terutama di lingkungan sekolah yaitu masalah sampah. Dengan adanya masalah tersebut perlu adanya perhatian khusus terhadap lingkungan. Fakta di atas memberitahukan bahwa perlu adanya kesadaran dari diri setiap individu untuk menjaga lingkungan. Maka dari itu gerakan peduli lingkungan sangat dibutuhkan untuk menjaga lingkungan agar tetap sehat. Sebagaimana dalam 5 nilai utama karakter prioritas PPK (penguatan pendidikan karakter) di Sekolah Dasar. Pendidikan karakter merupakan suatu tindakan atau upaya yang didalamnya memiliki unsur mendidik. Pendidikan karakter mempunyai peran yang penting untuk memperkuat mental dan karakter generasi penerus agar sejalan dengan tujuan pendidikan yakni membentuk karakter yang baik (Aria Prima Dewi PF, 2017).

Di dalam modul pelatihan penguatan pendidikan karakter (PPK) menjelaskan 5 nilai menjadi fokus PPK yaitu religius, nasionalis, mandiri, gotong royong, dan integritas. Dimana gerakan peduli lingkungan termasuk didalam nilai karakter nasionalis. Nilai nasionalis merupakan bagaimana cara kita besikap, 
berfikir dan berbuat yang menunjukan jiwa kepedulian, kesetian, penghargaan terhadap lingkungan, sosial, budaya, ekonomi, politik dan bangsa di atas kepentingan diri maupun kelompok. Nilai yang terkandung di dalam karakter nasionalis antara lain menjaga lingkungan, menjaga kekayaan alam, cinta tanah air, dan disiplin.

Menurut Nenggala (2007:173) seseorang bisa dikatakan memiliki sikap peduli lingkungan apabila : (1) menjaga atau memelihara kelestarian lingkungan yang ada sekitar (2) tidak menebang, mencabut atau mengambil tumbuhan yang berada dilingkungan sekitar (3) tidak mencoret-coret, muliskan tuisan di pohon, batu, jalan atau dinding dilingkungan sekitar (4) selalu membuang sampah pada tempatnya (5) tidak membakar sampah di lingkungan sekitar (6) melakukan atau melaksanakan kegiatan membersihkan lingkungan yang ada di sekitar (7) menimbun atau mengubur barang-barang bekas (8) Membersihkan sampah-sampah yang menyumbat saluran air. Pembentukan karakter peduli lingkungan di Sekolah Dasar dapat dilaksanakan memalui berbagai hal. Kegiatan tersebut dapat dilakukan secara bertahap dan melibatkan siswa dan warga sekolah lainnya, sehingga menjadi suatu kebiasaan (Widyaningrum, 2016).

Pendidikan karakter melibatkan semua kepentingan dalam pendidikan, baik pihak keluarga, sekolah, lingkungan sekolah, dan juga masyarakat luas. Pembentukan dan pendidikan karakter tidak akan berhasil jika antara lingkungan pendidikan tidak ada kesinambungan dan keharmonisan (Sukiningsih, 2019). Setelah melakukan observasi awal di SDN 55/I Sridadi peneliti menemukan bahwa di sekolah tersebut telah melakukan gerakan peduli lingkungan dimana tampak semua siswa pada pagi hari sebelum memulai kegiatan pembelajaran siswa membersihkan lingkungan sekolah, hal ini tidak hanya dilakukan oleh siswa saja melainkan guru dan bahkan kepala sekolah ikut serta dalam membersihkan lingkungan.

Setelah tampak di lapangan peneliti sedikit melakukan wawancara terhadap Kepala sekolah dan guru, dari wawancara tersebut dapat disimpulkan bahwasanya peran kepala sekolah ikut serta dalam adanya gerakan peduli lingkungan. Tidak hanya baru diterapkan melainkan sudah terlaksana program Sagusapo ( satu guru satu pohon ) dan program lainnya.

Dengan adanya permasalahan tersebut peneliti tertarik mengangkat permaslahan tersebut dalam penelitian guna memperdalam kajian mengenai gerakan peduli lingkungan tersebut. Dan peneliti mengambil Judul "Penerapan

Gerakan Lingkungan di SDN 55/I Sridadi".

\section{METODE}

\section{Tempat dan Waktu Penelitian}

Penelitian ini dilaksanakan pada semester Ganjil TA 2019/2020 di SD Negeri 55/I Sridadi, Kec.Muara Bulian, Kab.Batanghari, Provinsi Jambi. Dilaksanakan kurang lebih 2 bulan yaitu dari tanggal 4 Juli sampai 9 September 2019.

\section{Pendekatan dan Jenis Penelitian}

Pendekatan yang digunakan dalam penelitian ini adalah pendekatan kualitatif deskriptif karena dalam penelitian ini menghasilkan kesimpulan berupa data yang menggambarkan secara rinci, bukan data yang berupa angka-angka. Hal ini karena pendekatan kualitatif sebagai prosedur penelitian yang menghasilkan data deskriptif berupa kata-kata tertulis maupun lisan dari orang-orang maupun perilaku yang diamati. Penelitian kualitatif adalah suatu pendekatan ilmiah yang mengungkapkan situasi sosial tertentu dengan mendeskripsikan kenyataan secara 
benar, dibentuk oleh kata-kata berdasarkan teknik pengumpulan analisis data yang relevan yang diperoleh dari situasi alamiah.

Metode penelitian kualitatif adalah suatu metode penelitian yang digunakan untuk meneliti obyek alamiah yang berlandaskan pada filsafat postpositivisme, diamana peneliti sebagai instrumen kunci, teknik pengumpulan data dengan triangulasi, analisis data bersifat induktif atau kualitatif dan hasil penelitian kualitatif lebih menekankan makna dari pada generalisasi (Sugiono, 2014:15).

Penelitian kualitatif digunakan untuk mengetahui fenomena apa yang dialami oleh subyek penelitian, misalnya tindakan, motivasi, perilaku, persepsi dan lain-lain. Penelitian kualitatif memiliki dua tujuan utama yaitu menggambarkanmengungkap dan menggambarkanmenjelaskan.

Jenis dalam penelitian ini adalah fenomenologi. Penggunaan jenis penelitian ini dengan alasan bahwa fokus dalam penelitian ini adalah penerapan gerakan peduli lingkungan di lingkungan sekolah.

Fenomenologi merupakan sesuatu untuk mempelajari fenomena penampakan serta berbagai hal yang muncul dalam kehidupan kita dan makna yang kita miliki dalam pengalaman. Fokus perhatian fenomenologi tidak hanya sekedar fenomena tetapi juga bisa berupa pengalaman yang dialami langsung atau dari sudut pandang orang lain yang mengalaminya (Kuswarno, 2009:22).

\section{Data dan Sumber Data Data Penelitian}

Data dalam penelitian ini bersifat deskriptif karena peneliti akan menjelaskan fenomena mengenai penerapan gerakan peduli lingkungan di sekolah. Data dalam penelitian ini berupa wawancara dengan kepala sekolah dan guru, hasil pengisisan angket oleh siswa dan dokumentasi tentang penerapan gerakan peduli lingkungan di sekolah yang berupa foto-foto kegiatan yang dilakukan setiap pagi hari yaitu menyapu, memungut sampah, menyiram tanaman dan lain sebagainya.

\section{Sumber Data Penelitian}

Sumber data dalam penelitian ini adalah kepala sekolah, guru serta siswa SD Negeri 55/I Sridadi, Muara Bulian

\section{Teknik Pengambilan Sampel (Cuplikan)}

Teknik pengambilan data dilakukan secara snowball, didasarkan pada analogi bola salju, yang dimulai dengan yang kecil kemudian membesar secara bertahap karan ada penambahan salju ketika digulingan dalam hamparan salju. Ini dimulai dengan beberapa orang atau kasus, kemudian meluas berdasarkan hubungan-hubungan terhadap responden untuk dapat menemukan sample yang sulit di akses, atau untuk memperoleh informasi dari responden mengenai permasalahan yang spesifik atau tidak terlihat jelas di dunia nyata, maka teknik snowball merupakan salah satu cara yang dapat di andalkan dan sangat bermanfaat dalam menemukan responden yang dimaksud sebagai sasaran penelitian melalui keterkaitan hubungan dalam satu jaringan sehingga tercapai jumlah sample yang dibutuhkan.

\section{Teknik Pengumpulan Data}

Teknik pengumpulan data merupakan langkah yang paling strategis dalam penelitian, karena seperti yang diketahui tujuan dari penelitian untuk mendapatkan data. Tanpa mengetahui bagaimna teknik pengumpulan data, peneliti tidak akan mendapatkan data sesuai dengan standar data yang ditetapkan (Sugiyono, 2012).

Teknik pengumpulan data yang digunaka dalam penelitian ini berupa observasi, wawancara, dan dokumentasi.

\section{Observasi}


Observasi menurut sutopo (1996:59) digunakan untuk menggali data dari sumber data yang berupa peristiwa, tempat atau lokasi, dan benda, serta rekaman gambar. Sementara itu, Haradi (1991:100) mengartikan observasi adalah pengamatan atau pencatatan secara sistemik terhadap gejala yang tampak pada objek penelitian. Observasi sendiri menururt burhan bumin (2012:190-191) ada dua tipe, yakni observasi tidak langsung dan observasi partisipan. Observasi tidak langsung adalah observasi dimana seorang peneliti tidak masuk ke dalam masyarakat tersebut. Bisa saja ia hanya melihat dengan sepasang matanya mengenai kegiatan dan benda-benda budaya atau dibantu dengan alat-alat lain seperti kamera. Sedangkan observasi partisipan merupakan kegiatan pengamatan langsung dengan melibatkan peneliti itu sendiri serta masyarakat yang menjadi obyek penelitian.

Dalam penelitian ini observasi yang digunakan adalah observasi pertisipan karena dalam kegiatan observasi awal peneliti melibatkan dirinya langsung dalam kegiatan di lingkungan sekolah (Rokhmani, 2016)

\section{Wawancara}

Wawancara pada penelitian ini berupa wawancara tidak terstruktu dimana wawancara tidak terstruktur atau bebas peneliti tidak menggunakan pedoman wawancara yang telah tersusun secara sistemtais dan lengkap untuk mengumpulkan datanya.

Pedoman yang digunakan hanya garis-garis besar permasalahannya. Wawancara tidak terstruktur digunakan dalam penelitian yang lebih mendalam untuk responden.

Melalui wawancara tidak terstruktur ini peneliti menanya tentang penerapkan gerakan peduli lingkungan di SDN 55/I Sridadi. Disini penenliti menanya langsung bertanya kepada subjek penelitian yaitu kepala sekolah dan guru yang ada di SDN 55/I Sridadi.

\section{Tabel 3.1 Kisi-kisi Wawancara}

\begin{tabular}{|c|c|}
\hline No & Butir pertanyaan \\
\hline 1 & $\begin{array}{l}\text { Apakah warga dilingkungan sekolah menjaga atau memelihara kelestarian lingkungan } \\
\text { sekitar sekolah? }\end{array}$ \\
\hline 2 & $\begin{array}{l}\text { Apakah warga lingkungan sekolah tidaka menebang, mencabut, atau mengambil } \\
\text { tumbuhan yang terdapat disekolah? }\end{array}$ \\
\hline 3 & $\begin{array}{l}\text { Apakah warga lingkungan sekolah tidak mencoret-coret, lingkungan dan fasilitas yang } \\
\text { ada di sekolah? }\end{array}$ \\
\hline 4 & Apakah warga lingkungan sekolah selalu membuang sampah pada tempatnya? \\
\hline 5 & Apakah warga lingkungan sekolah tidak membakar sampah dilingkungan sekolah? \\
\hline 6 & Apakah warga lingkungan sekolah melaksanakan kegiatan membersihkan lingkungan? \\
\hline 7 & Apakah warga lingkungan sekolah menimbun barang-barang bekas? \\
\hline 8 & $\begin{array}{l}\text { Apakah warga lingkungan sekolah membersihkan sampah-sampah yang menyumbat } \\
\text { saluran air? }\end{array}$ \\
\hline
\end{tabular}

Sumber : Nenggala (2017:173) 


\section{Dokumentasi}

Dokumen meruapakan catatan mengenai peristiwa yang sudah berlalu. Menurut Sugiyono (2016:329) dokumentasi biasa digunakan sebagai pelengkap data dari hsil observasi, wawancara maupun penyebaran angket yang sesuai dengan masalah yang diteliti.

Dalam hal ini peneliti mengambil dokumen-dokumen yang berkaitan dengan penerapkan gerakan peduli lingkungan. Foto atau rekaman yang digunakan untuk memperoleh data yang tidak dapat ditemukan secara tertulis sekaligus menjadi pelengkap sebagai bukti bagi peneliti. Foto yang digunakan yaitu foto yang diperoleh langsung oleh peneliti di sekolah dasar.

\section{Teknik Uji Validitas Data}

Teknik validitas merupakan derajat ketepatan data yang terjadi pada objek penelitian dengan daya yang dapat dilaporkan oleh peneliti. Dengan demikian data yang valid adalah data yang tidak memiliki perbedaan antara data yang dilaporkan oleh peneliti dengan data sesungguhnya yang terjadi dilapangan.

\section{Triangulasi}

Triangulasi dalam pengujian kredibilitas adalah pengecekan data dari berbagai sumber dengan berbagai cara dan waktu. Teknik triangulasi ini dapat diperoleh berbagai variasi informasi yang seluas-luasnya.

Dalam penelitian ini peneliti menggunakan triangulasi teoritik untuk menguji kredibilitas data dengan cara mengecek data yang diperoleh memalui teori ahli.

\section{Teknik Analisis Data}

Analisis data dalam penelitian kualitatif dilakukan sebelum pengumpulan data, pada saat pengumpulan data berlangsung, dan setelah pengumpulan data dalam priode tertentu. Sebelum melakukan wawancara peneliti melakukan pemberian angket untuk mengetahui keadaan lingkungan sekolah. Pada saat wawancara, peneliti telah menganalisis terhadap jawaban yang diwawancarai. Bila jawaban yang dianalisis belum sesuai dengan keadaan lingkungan, maka peneliti melanjutkan dengan pertanyaan lagi.

Adapun langkah-langkah dalam menganalisis data deskriptif kualitatif menurut Miles dan Huberman (Sugiyono, 2009:247) adalah sebagai berikut :

a. Data Reduction (Reduksi data)

Pada tahap ini data yang terkumpul baik yang berasal dari hasil pengisian angket dan dokumentasi dirangkum, diseleksi dan difokuskan. Mereduksi data dilakukan dengan cara memilih dan menyisihkan data yang kurang bermakna dan menatanya.

b. Data Display (Penyajian data)

Penyajian data kualitatif dalam penelitian ini dilakukan dalam bentuk uraian singkat, jelas dan lengkap. Penyajian data ini untuk mempermudah tim peneliti memahami dalam hubungannya terhadap aspek yang diteliti.

c. Conclution/verification (Kesimpulan dan Verifikasi)

Penarikan kesimpulan dilakukan secara bertahap yang berupa kesimpulan sementara yang ditarik dari hasil angket dan wawancara kepala sekolah dan guru.

\section{Prosedur Penelitian}

1. Penelitian dilakukan melalui studi pendahuluan menggunakan observasi awal untuk melihat kondisi di SDN 55/I Sridadi

2. Melakukan indentifikasi mengenai masalah

3. Melakukan pefokusan masalah

4. Melakukan penelitian mengenai penerapakan gerakan peduli lingkungan 
5. Melakukan pengumpulan data yang didapat dari hasil wawancara dan penyebaran angket

6. Semua data hasil penelitian dilakukan analisis data untuk direduksi, disajikan, dan penarikan kesimpulan.

\section{HASIL PEMBAHASAN}

Hasil penelitian mengenai gerakan peduli ligkungan di SDN 55/I Sridadi dilaksanakan dengan cara melihat kegiatan rutin yang dilaksanakan setiap harinya oleh seluruh warga sekolah baik siswa maupun guru serta kepala sekolah. Siswa, guru maupun kepala sekolah tururt serta dalam menjaga kelestarian lingkungan sekolah dengan cara diadakannya program-program yang mendukung kegiatan ini. Seperti adanya program SaGuSaPo (Satu guru satu pohon). Dimana guru dan kepala sekolah dan warga lingkungan sekolah membawa satu pohon untuk ditanam di lingkungan sekolah dan memiliki tanggung jawab merawat dan menjaga pohon tersebut hingga tumbuh besar.

Warga di lingkungan sekolah sama-sama membersihkan dan menjaga di lingkungan sekolah dengan menyapu halaman setiap pagi sebelum pembelajaran dimulai, dimana guru bertanggung jawab mengontrol kegiatan pembersihan lingkungan yang dilakukan oleh siswa. Guru tidak hanya mengontrol siswa tetapi guru juga ikut serta membersihkan lingkungan sekolah sebagai contoh tauladan bagi siswanya.

Tidak hanya itu warga sekolah juga dilarang mencoret-coret dinding sekolah, poho maupun fasilitas yang ada di sekolah trsebut, demi menjaga ingkungan sekolah agar tetap baik. Siswa juga diarahkan agar membuang sampah pada tempatnya dengan di sediakan tempat sampah di setiap ruang kelas serta peralatan kebersihan lainnya serta adanya pembuangan sampah akhir yang terletak di belakang sekolah. Begitupun dengan kantin yang berada dilingkungan sekolah, pihak kantin diarahkan agar tetap selalu menjaga kebersihan sekitar dan pihak sekolah bekerja sama dengan pihak kantin untuk mengurangi sampah plastik dengan tidak menggunakan kantong plastik sebagai wadah makanan melainkan menggunakan peralatan makan.

Sisa olahan sampah yang telah terkumpul tidak dibakar melainkan dengan cara menimbun barang-barang tersebut. Hal ini juga dilakukan untuk mengurangai polusi udara. Warga sekolah tidak hanya membersihkan lingkungan kotor yang terlihat saja tetapi juga membersihkan saluran-saluran air agar tidak menyumbat aliran air. Terlihat jelas Wc yang terdapat di lingkungan tersebut terjaga kebersihannya dikarenakan warga sekolah rutin membersihkan Wc tersebut melalui piket rutin yang telah ditetapkan. Guru memberikan contoh dengan menunjukkan kumpulan sampah-sampah agar siswanya mengikuti cara gurunya. Pada musim kemarau warga sekolah diintruksikan atau ditugaskan untuk membawa air ke sekolah guna menyiram ketanaman dan jalan agar tidak gersang. Guru memberikan hukuman sebagai efek jerah kepada siswa yang tidak mengerjakan tugasnya yang telah ditetapkan gurunya.

\section{SIMPULAN DAN SARAN}

Berdasarkan hasil penelitian dan pembahasan di bab IV simpulan di penelitian ini disajikan sebagai berikut :

Gerakan peduli lingkungan yang diterapkan di SDN 55/I Sridadi dilaksanakan melalui program-program serta kebijakan yang di terapkan oleh pihak sekolah terkait semua hal yang menyangkut kebersihan lingkungan sekolah, dimana guru tidak hanya memerintahkan siswa untuk menjaga 
lingkungan sekolah tetapi guru juga ikut serta dalam menjaga lingkungan sekolah tersebut. Hal ini dilihat dari kegiatan rutin yang dilaksanakan setiap hari sebelum pembelajaran dimulai sampai pembelajaran selesai dimana warag sekolah bersama-sama menjaga kebersihan lingkungan mulai dari setiap pagi menyapu dan membersihkan lingkungan sampai tidak membuang sampah sembaranagan di lingkungan sekolah selama warga sekolah berada di sekolah.

\section{DAFTAR PUSTAKA}

Aria Prima Dewi PF, K. (2017). The Empowerment Of Role Of The Family In Developing Character Of Environmental Awareness In Elementary School-Age Children. Vidyottama Sanatana: International Journal of Hindu Science and Religious Studies, 1(1), 77. https://doi.org/10.25078/ijhsrs.v1i1.1 57

Dewi P.F., K. A. P., \& Budimansyah, D. (2016). The Community-Based Value Education to Develop Environmental Awareness Characters for Elementary School Students. https://doi.org/10.2991/icse15.2016 .23

Ngalawiyah, L. (2014). STUDI
DESKRIPTIF IMPLEMENTASI

NILAI PEDULI LINGKUNGAN

MENUJU SEKOLAH ADIWIYATA DI SDN TUKANGAN

YOGYAKARTA. In British Journal of Psychiatry.

https://doi.org/10.1192/bjp.205.1.76a

Rokhmani, T. A. (2016). Implementasi

Pendidikan Karakter Peduli Lingkungan. Jurnal Pendidikan Guru Sekolah Dasar, 5(3), 295-306.

Sukiningsih, N. W. (2019).

PENANAMAN NILAI-NILAI

KARAKTER PADA SISWA SEKOLAH DASAR MELALUI

CERITA RAMAYANA. Adi Widya: Jurnal Pendidikan Dasar. https://doi.org/10.25078/aw.v4i1.930

Trahati, M. R. (2015). IMPLEMENTASI PENDIDIKAN KARAKTER PEDULI LINGKUNGAN DI SEKOLAH DASAR NEGERI TRITIH WETAN 05 JERUKLEGI CILACAP. Jurnal Pendidikan Guru Sekolah Dasar. https://doi.org/10.1145/3132847.3132 886

Widyaningrum, R. (2016). Pembentukan Karakter Peduli Lingkungan Siswa Sekolah Dasar Melalui Sekolah Peduli dan Berbudaya Lingkungan. Widya Wacana. 